\title{
TÉCNICAS PARA AVALIAÇÃO DO EFEITO “IN VITRO” DE FUNGICIDAS SOBRE BACILLUS THURINGIENSIS VAR. KURSTAKI*
}

\author{
E.R.L. Silva ${ }^{1 * *}$, L.F.A. Alves ${ }^{2 * *}$, L. Sene ${ }^{3}$, J. Santos ${ }^{2}$, A.K. Bonini' ${ }^{2}$, M. Potrich ${ }^{1 * *}$, P.M.O.J. Neves ${ }^{1 * * *}$ \\ ${ }^{1}$ Universidade Estadual de Londrina, Centro de Ciências Agrárias, Departamento de Agronomia, Laboratório \\ de Entomologia, Rod. Celso Garcia Cid, PR 445, km 380, CEP 86051-990, Londrina, PR, Brasil. E-mail: \\ evertonloz@gmail.com
}

\section{RESUMO}

\begin{abstract}
Objetivou-se comparar técnicas para a avaliação "in vitro" do efeito de fungicidas sobre Bacillus thuringiensis var. kurstaki (Btk). Foram testados os fungicidas epoxiconazole, fentin hidróxido, azoxystrobin, tebuconazole e carbendazin em duas concentrações, sobre células e esporos, em ágar nutriente (AN) - sólido (MS) e caldo nutriente (CN) - líquido (ML), além da metabolização (MT) destes por Btk. Para células em AN, os fungicidas foram testados incorporados ao meio e em discos de papel-filtro. Avaliou-se, respectivamente, as UFC/mL e a formação de halo de inibição. Para células, a mistura Bt + produtos $+\mathrm{CN}$ foi incubada em erlemmeyers $\left(30 \pm 2^{\circ} \mathrm{C}, 150 \mathrm{rpm}, 24 \mathrm{~h}\right)$, e em seguida, diluida e inoculada em AN, avaliandose o número de UFC/mL. Os testes de MT e esporos foram realizados em líquido (água). O efeito dos produtos variou conforme a concentração, técnica, tempo de contato e fase/estágio do desenvolvimento do patógeno. O teste ML é o mais indicado para a avaliação do efeito em células, sendo observado que a maioria dos fungicidas mostrou-se compatível com as mesmas, e apenas epoxiconazole e azoxystrobin foram metabolizados. Fentin hidróxido foi o único incompatível com esporos.
\end{abstract}

PALAVRAS-CHAVE: Bactérias entomopatogênicas, seletividade, compatibilidade.

\section{ABSTRACT}

TECHNIQUESFOREVALUATIONOFTHEIN-VITROEFFECTOFFUNGICIDESONBACILLUS THURINGIENSIS VAR. KURSTAKI. The aim of this study was to compare techniques for the invitro evaluation of the effect of fungicides on Bacillus thuringiensis var. kurstaki(Btk). The fungicides epoxiconazole, fentin hydroxide, azoxystrobin, tebuconazole, and carbendazim were tested at two concentrations, on cells and spores, in nutrient agar (NA) - solid medium (SM), and in nutrient broth (NB) - liquid medium (LM), with an evaluation also being made of their metabolization (MT) by Btk. For cells, the fungicides in NA were tested incorporated into the medium and on filterpaper disks. The evaluation consisted, respectively, of the number of $\mathrm{CFU} / \mathrm{mL}$ and of the formation of an inhibition halo. For cells, the $\mathrm{Bt}+$ products $+\mathrm{NB}$ mixture was incubated in Erlenmeyer flasks $\left(30 \pm 2^{\circ} \mathrm{C}, 150 \mathrm{rpm}, 24 \mathrm{~h}\right)$ and then was diluted and inoculated onto NA; the number of $\mathrm{CFU} / \mathrm{mL}$ was evaluated. The $\mathrm{MT}$ and spore tests were performed in liquid medium (water). The effects of the products varied with their concentration, technique used, contact time, and developmental stage of the pathogen. The LM test is the most recommendable for evaluating the effect on cells. It was observed that most fungicides were compatible with cells, and only epoxiconazole and azoxystrobin were metabolized. Fentin hydroxide was the only fungicide incompatible with spores.

KEY WORDS: Entomopathogenic bacteria, selectivity, compatibility.

\footnotetext{
${ }^{2}$ Universidade Estadual do Oeste do Paraná, CCBS, Laboratório de Zoologia, Cascavel, PR, Brasil.

${ }^{3}$ Universidade Estadual do Oeste do Paraná, Laboratório de Controle Microbiológico de água, alimentos e medicamentos, Cascavel, PR, Brasil.

*Parte da dissertação de mestrado do primeiro autor - Universidade Estadual do Oeste do Paraná, Unioeste, Campus de Marechal Cândido Rondon.

**Programa de Pós-graduação em Agronomia, Nível Doutorado.

***Bolsista de Produtividade Científica - CNPq.
} 


\section{INTRODUÇÃO}

Os produtos fitossanitários estão inseridos em um pacote tecnológico indispensável para a condução do atual modelo de produção agrícola, sendo a utilização dos mesmos concomitante à crescente demanda para produção de alimentos e lucratividade.

Ocontrolebiológico, com destaque ao microbiano, é uma das estratégias viáveis para o controle de populações de insetos-praga nos programas de Manejo Integrado de Pragas (MIP), encontrando nesses programas as melhores oportunidades de aplicação (SOSA-GÓmeZ \& Moscardi, 2003).

Dentre os entomopatógenos, Bacillus thuringiensis (Bt) tem sido utilizado há mais de 50 anos para o controle de pragas agrícolas e insetos vetores de doenças. Atualmente, é o ingrediente ativo mais utilizado comercialmente nos bioinseticidas, com um mercado atual variando de $80 \%$ (MorAes et al., 1998) até 90 a 95\% (VAladares-Ingliset al.,1998), representando $1 \%$ deste mercado na década de 1990 (Moraes et al., 1998). No Brasil, B. thuringiensis var. kurstaki (Btk) é utilizado em cerca de 150.000 ha para o controle de aproximadamente 30 pragas, nas diversas culturas (PolAnCZYK, 2004).

De acordo com Alves et al. (1998), o controle integrado com a utilização de produtos fitossanitários seletivos aos agentes de controle biológico pode ser uma das estratégias mais seguras e eficientes, principalmente nas culturas onde a utilização destes produtos seja indispensável, como as frutíferas de clima temperado, citros, café, algodão, soja, dentre outras. Além disso, a ação dos agentes de controle microbiano pode ser estimulada, reprimida ou permanecer inalterada mediante aplicação de produtos fitossanitários (SOSA-GómeZ \& MoscARDI, 2003).

A utilização de produtos seletivos contribui para a conservação de populações de inimigos naturais, potencializando o controle biológico. Também pode reduzir o uso excessivo de produtos fitossanitários, custos ao produtor e contaminação ambiental.
São várias as técnicas utilizadas para a avaliação do efeito de produtos fitossanitários sobre bactérias. DOUGHERTY et al.(1971) e JiMENEZet al.(1989) avaliaram os efeitos de produtos fitosssanitários sobre esporos de Bacillus thutingiensis var. thuringiensis (Bt) através da técnica de discos de papel impregnados nas caldas dos produtos. Por sua vez,SutTeret al.(1971) estudaram os efeitos de inseticidas sobre células de Bt em meio de cultura líquido. Além disso, Chenet al. (1974) testaram duas formulações de Bt e diferentes concentrações de inseticidas. Ainda, por meio da técnica de mistura dos produtos ao meio de cultura fundido, SALERNO et al. (1999) avaliaram o efeito de herbicidas, fungicidas e inseticidas sobre 16 cepas de Bt eBATISTA FilHo et al. (2001) avaliaram o efeito de inseticidas sobre Bt em campo e laboratório, nas concentrações máxima e mínima recomendadas.

Neste sentido, estudos sobre o efeito de produtos fitossanitários em Bt são necessários, umavezquetais estudos são escassos, desatualizados, sendo em sua maioria realizados com inseticidas, e semuma padronização na metodologia.

Assim, este trabalho teve por objetivo testar e comparar diferentes técnicas para a avaliação do efeito de fungicidas sobre células e esporos de Btk e testar a metabolização dos fungicidas pela célula.

\section{MATERIAL E MÉTODOS}

Os experimentos foram conduzidos no Laboratório de Zoologia de Invertebrados (CCBS) e nos Laboratórios de Bioquímica e Controle Microbiológico de Água, Alimentose Medicamentos(CCMF) da Unioeste, Campus de Cascavel.

Foram testados fungicidas (Tabela 1), na concentração recomendada pelo fabricante e na metade desta, sobre células e esporos deBacillus thuringiensis var. kurstaki (Btk) isolada de produto comercial Dipel PM ${ }^{\circledR}$. Os testes foram realizados em meio de cultura sólido (MS) e líquido (ML). Além disso, testou-se a capacida-

Tabela 1 - Fungicidas utilizados nos experimentos.

\begin{tabular}{|c|c|c|c|c|}
\hline \multicolumn{2}{|l|}{ Nome } & \multirow[t]{2}{*}{ Formulação } & \multirow[t]{2}{*}{ Grupo químico } & \multirow[t]{2}{*}{ Concentração Recomendada L/ ha ${ }^{1}$} \\
\hline Técnico & Comercial & & & \\
\hline Fentin Hidróxido & Brestanid & SC & Organoestânico & 0,5 \\
\hline Carbendazin & Derosal & SC & Benzimidazólico & 0,5 \\
\hline Tebuconazole & Folicur & $\mathrm{CE}$ & Triazol & 0,5 \\
\hline Epoxiconazole & Opera & SE & Estrobilurinas e triazol & 0,5 \\
\hline Azoxystrobin & Priori & SC & Estrobilurinas & 0,4 \\
\hline
\end{tabular}

${ }^{1}$ Diluição padronizada em 200L $\mathrm{H}_{2} \mathrm{O} /$ há.

$\mathrm{SC}=$ Suspensão Concentrada; $\mathrm{CE}=$ Concentração Emulsionável; $\mathrm{SE}=$ Suspo-Emulsão. 
de de metabolização (MT) dos produtos por Btk, bem como o efeito destes produtos sobre esporos em ML. As células foram quantificadas indiretamente por meio de espectrofotometria e correlação em curva padrão, a partir de um pré-cultivo de amostra pura em meio líquido.

\section{Efeito sobre células vegetativas}

Em meio sólido

Mistura no meio. Os fungicidas, na concentração recomendada e na metade desta, foram adicionados em meioágar nutriente (AN) fundido $\left(45-50^{\circ} \mathrm{C}\right)$, ainda não solidificado. Após solidificação do meio em placas-de-Petri, para cada tratamento, foram inoculadas suspensões de células, do pré-cultivo, nasconcentrações $1,7 \times 10^{4}, 1,7 \times 10^{3} \mathrm{e} 1,7 \times 10^{2} \mathrm{UFC} / \mathrm{mL}$, sendoduas placas por suspensão com cinco pontos de $5 \mu \mathrm{L}$ cada. Após incubação $\left(30 \pm 2{ }^{\circ} \mathrm{C} ; 20 \mathrm{~h}\right)$ foram quantificadas as UFC/mL. Foi classificado como compatível com a célula de Btk o produto que permitiu crescimento, significativamente igual ou maior da testemunha, e incompatível o que não permitiu o crescimento bacteriano e ou foi significativamente menor que o da testemunha.

\section{Contato com papel-filtro}

Discos de papel-filtro de $1 \mathrm{~cm}$ de diâmetro foram mergulhados nas caldas dos fungicidas, nas duas concentrações estudadas, e colocados em contato com a superfície do meio de cultura já inoculado com $0,1 \mathrm{~mL}$ do pré-cultivo $\left(1,2 \times 10^{6} \mathrm{UFC} / \mathrm{mL}\right)$ distribuído na superfície do meio com alça de Drigalsky, sendo duas placas com cinco discos cada. Após incubação $\left(24 \mathrm{~h}, 30 \pm 2^{\circ} \mathrm{C}\right)$, avaliou-se a presença do halo de inibição no crescimento das colônias ao redor dos discos. O produto que apresentou halo de inibição ao redor do disco de papel foi classificado como incompatível, ao passo que o produto que não apresentou halo foi classificado como compatível com células de Btk. O produto que promoveu a formação de halo de inibição ao redor dos discos de papel, porém com a presença de UFC, foi classificado como parcialmente compatível ou parcialmente incompatível.

\section{Em meio líquido}

Os fungicidas, nas concentrações estudadas, foram adicionados ao meio de cultura caldo nutriente (CN), em frascos erlenmeyer com capacidade de 250 $\mathrm{mL}$, juntamente com uma alíquota de Btk na concentração de $1 \times 10^{7} \mathrm{UFC} / \mathrm{mL}$ para cada frasco, sendo as misturas incubadas em agitador horizontal $\left(30 \pm 2^{\circ}\right.$ C, $150 \mathrm{rpm}, 24 \mathrm{~h})$. Posteriormente, cada tratamento foi submetido ao método de diluições decimais $\left(10^{-3}, 10^{-4}\right.$ e $\left.10^{-5}\right)$, sendo cada uma destas suspensões inoculadas em duas placas de Petri com cinco pontos de $5 \mu \mathrm{L}$ em cada uma. Após incubação $\left(30 \pm 2^{\circ} \mathrm{C}, 20 \mathrm{~h}\right)$, foi avaliado o crescimento vegetativo, quantificando-se o número das UFC/mL em cada ponto.

\section{Capacidade de metabolização}

Foram utilizados frascos erlenmeyer com capacidade de $250 \mathrm{~mL}$, aos quais foram inoculados $0,5 \mathrm{~mL}$ $\left(7 \times 10^{6} \mathrm{UFC} / \mathrm{mL}\right)$ do pré-cultivo em $50 \mathrm{~mL}$ de água estéril acrescida dos fungicidas nas concentrações estudadas. Os frascos foram incubados em agitador horizontal $\left(30 \pm 2^{\circ} \mathrm{C}, 150 \mathrm{rpm}, 24 \mathrm{~h}\right)$. Após feitas diluições decimais $\left(10^{-3}, 10^{-4}\right.$ e $\left.10^{-5}\right)$, as suspensões foram inoculadas, sendo todos os procedimentos e condições os mesmos utilizados na técnica em ML.

Previamente, à incubação do Btk + fungicidas em agitador horizontal, e ao final do período de $24 \mathrm{~h}$, mediu-se o $\mathrm{pH}$ da mistura de cada frasco para verificação de uma possível mudança de $\mathrm{pH}$, em caso de metabolização.

\section{Efeito sobre os esporos}

\section{Em meio líquido}

Após preparação das caldas, utilizando-se água esterilizada, conforme descrito para a técnica em ML, cada frasco recebeu uma suspensão de $10^{6} \mathrm{UFC} / \mathrm{mL}$ preparada a partir de produto comercial ajustada da diluição de $5 \mathrm{~g}$ do produto em $20 \mathrm{~mL}$ de água esterilizada. Os frascos foram incubados em agitador horizontal $\left(30 \pm 2^{\circ} \mathrm{C}, 150 \mathrm{rpm}, 2 \mathrm{~h}\right)$ com coletas de alíquotas de $1 \mathrm{~mL}$ de cada frasco, nos tempos de uma e duas horas. A partir de cada coleta procedeu-se uma diluição decimal e inoculação em placas de Petri com meio AN. Todos os procedimentos e condições para a inoculaçãoeincubaçãoforamosmesmosutilizadosna técnica em ML. Avaliou-se a germinação dos esporos, nos respectivos tempos, quantificando-se as UFC/mL. Foiclassificado comocompatível com esporos o produto que permitiu germinação e crescimento significativamente igual ou maior ao da testemunha, e incompatível, o que não permitiu a germinação ou foi significativamente menor que o da testemunha.

Em todas as técnicas, a testemunha constou do tratamento sem a adição dos fungicidas.

\section{Análise Estatística}

Exceto para a técnica dos discos impregnados, os experimentosforam realizadossegundo delineamento experimental inteiramente casualizado, considerando cada ponto inoculado nas placas como repetição. Os dados foram submetidos à análise de variância pelo teste F e as médias comparadas entre si pelo teste de Tukey, ambos com 5\% de significância. Para o teste com esporos foi utilizada a análise de parcelas subdivididas no tempo (Split Plot), sendo as médias com- 
paradas entre si pelo teste de Tukey a $5 \%$ de significância. Quandonecessário, os dados foram previamente transformados por $\sqrt{\mathrm{x}+1}$. Para todas as análises utilizou-se o programa estatístico SISVAR (FERREIRA, 2005).

\section{RESULTADOS E DISCUSSÃO}

\section{Efeito sobre células vegetativas}

\section{Em meio sólido}

Mistura no meio. Nesta técnica, a maioria dos produtos foi classificada como incompatível com as células de Btk, sendo que os fungicidas epoxiconazole, tebuconazole, azoxystrobin e fentin hidróxido, independentemente da concentração utilizada, não permitiram o desenvolvimento vegetativo de Btk. Apenas carbendazin, na metade da concentração recomendada, permitiu a formação de UFC $/ \mathrm{mL}$, significativamente semelhante à testemunha, sendo que na concentração recomendada a média de UFC/mL foi significativamente menor que ambos os tratamentos. Estes resultados discordam dos obtidos porSALERNo etal.(1999), que na concentração recomendada verificaram o de- senvolvimento das 16 variedades de Bt testadas. A diferença entre os dois resultados está na formulação do produto utilizada, que foi pó molhável para SALERNo et al.(1999) e suspensão concentrada neste trabalho (Tabela 2).

Em testes semelhantes foi verificadoque o efeito de inseticidas sobre Bt variou de acordo com produtos e as concentrações utilizadas (BATISTAFILHo et al.,2001).

\section{Contato com papel-filtro}

Epoxiconazole e azoxystrobin, em ambas as concentrações, e carbendazin, na metade da concentração recomendada, foram classificados como compatíveis com Btk, pois não houve formação de halo de inibição em nenhuma repetição. Carbendazin, na concentração recomendada, apresentou três discos com a formação de halo com algumas UFC, sendo, portanto, classificado como compatível. Por outro lado, o produto tebuconazole, em ambas as concentrações, apresentou halo de inibição em todos os discos, porém com algumas UFC, sendo classificado como parcialmente compatível com as células de Btk. Fentin hidróxido foi o único produto classificado como incompatível, pois, em ambas as concentrações, apresentou halo de inibição em todos os discos.

Tabela 2 - Média de UFC/mL ( $\pm \mathrm{EP})$ de $B$. thuringiensis var. kurstaki incubado em caldo nutriente $\left(30 \pm 2^{\circ} \mathrm{C}\right.$ e $150 \mathrm{rpm}$, por $24 \mathrm{~h})$ e inoculado $\left(10^{-4}\right)$ em ágar nutriente misturado com diferentes concentrações de fungicidas.

\begin{tabular}{|c|c|c|c|c|}
\hline Tratamentos & Conc. L/ha ${ }^{1}$ & $\begin{array}{l}\text { Média UFC } / \mathrm{mL} \\
\qquad\left(\times 10^{6}\right)\end{array}$ & $\begin{array}{l}\text { \% Relação à } \\
\text { Testemunha }^{2}\end{array}$ & $\begin{array}{l}\text { Dif. Inóc. Inic. }{ }^{4} \\
\left(\times 10^{6}\right) \text { UFC/ mL }\end{array}$ \\
\hline Testemunha & - & $11,6 \pm 0,57 \mathrm{a}$ & - & $-5,4$ \\
\hline Carbendazin & $0,25(1 / 2 R)$ & $10,4 \pm 0,99 \mathrm{a}$ & $-10,3$ & $-6,6$ \\
\hline Carbendazin & $0,5(\mathrm{R})$ & $6,4 \pm 0,49 \mathrm{~b}$ & $-44,8$ & $-10,6$ \\
\hline Epoxiconazole & $0,5(\mathrm{R})$ & $0,0 \mathrm{c}$ & $-^{3}$ & - \\
\hline Epoxiconazole & $0,25(1 / 2 R)$ & $0,0 \mathrm{c}$ & - & - \\
\hline Tebuconazole & $0,5(\mathrm{R})$ & $0,0 \mathrm{c}$ & - & — \\
\hline Tebuconazole & $0,25(1 / 2 R)$ & $0,0 \mathrm{c}$ & - & - \\
\hline Azoxystrobin & $0,4(\mathrm{R})$ & $0,0 \mathrm{c}$ & - & — \\
\hline Azoxystrobin & $0,2(1 / 2 \mathrm{R})$ & $0,0 \mathrm{c}$ & - & - \\
\hline Fentin Hidróxido & $0,5(\mathrm{R})$ & $0,0 \mathrm{c}$ & - & - \\
\hline Fentin Hidróxido & $0,25(1 / 2 \mathrm{R})$ & $0,0 \mathrm{c}$ & - & - \\
\hline
\end{tabular}

Médias seguidas pela mesma letra minúscula na coluna, não diferem significativamente entre si pelo teste de Tukey $(\alpha=5 \%)$.

${ }^{1}$ Concentração utilizada dos produtos: $\mathrm{R}=$ recomendada, $1 / 2 \mathrm{R}=$ metade da recomendada.

${ }^{2}$ Fórmula: [(Média de UFC/mL do tratamento/ Média de UFC/mL da testemunha $\times 100$ ) - 100], sendo os valores positivos para aumento de UFC e negativos para a redução em relação à testemunha.

${ }^{3}$ Cálculo não realizado por não haver formação de UFC.

${ }^{4}$ Diferença do inóculo inicial = [(Média de UFC $/ \mathrm{mL}$ do patógeno inoculada antes da incubação nos frascos Erlenmeyer $)$ - (Média de UFC/mL do patógeno obtida após 24h de incubação )], sendo os valores positivos para crescimento da bactéria (aumento de UFC) e negativos para morte da bactéria (diminuição das UFC) em relação ao inóculo inicial. 
Essa variação na classificação de compatibilidade com células de Btk também foi verificada por Dougherty (1971) em testes com inseticidas e herbicidas. Entretanto, o autor não verificou diferença na classificação de compatibilidade com relação às concentrações dos fungicidas, discordando deJIMENEZ et al. (1989), que observaram variação do halo conforme a categoria do produto testado e a concentração utilizada. Os tratamentos com a metade da concentração recomendada foram compatíveis com Bt (JIMENEZ et al., 1989).

\section{Em meio líquido}

A maioria dos fungicidas mostrou-se incompatível com as células de Btk. Porém, epoxiconazole, na metade da concentração recomendada, estimulou o desenvolvimento da bactéria, a presentando média de $\mathrm{UFC} / \mathrm{mL}$ significativamente superior aos demais tratamentos, com aumento de 333,8\%, em relação à testemunha. Azoxystrobin, na metade da concentração recomendada, e epoxiconazole na concentração recomendada, também apresentaram médias de UFC / $\mathrm{mL}$ significativamente iguais à testemunha, porém, com menor aumento (Tabela 3).

Em técnica semelhante, com inseticidas, SuTTERet al. (1971) verificaram que B. thuringiensis var. thuringiensis se comportou de forma diferente na presença e ausência de determinados inseticidas e em relação às concentrações utilizadas. Além disso, observaram inibição da multiplicação bacteriana por alguns inseticidas e a compatibilidade, sem inibição, com outros. Da mesma forma, MorRIs (1975) observou variação conforme as concentrações e o produto utilizado.

Carbendazin, em ambas as concentrações, e azoxystrobin, na concentração recomendada, apresentaram menores médias de UFC/mL do que a testemunha (Tabela 3). Contudo, quando tais médias foram comparadas à concentração do inóculo inicial nos frascos erlenmeyer, verificou-se que houve crescimento bacteriano. Tal fato evidencia, assim como na técnica de discos impregnados, uma possível seleção de população resistente, uma vez que a população inoculada se manteve e cresceu, porém numa menor velocidade que no tratamento testemunha (Tabela 3).

Tal resistência pode se atribuir à capacidade de metabolizar o produto ou algum de seus componentes, apresentada por indivíduos da população, como também observado por SuTTER et al. (1971).

Somente os produtos tebuconazole e fentin hidróxido, em ambas as concentrações, foram incompatíveis, sem a presença de UFC/mL (Tabela 3).

Tabela 3 - Média de UFC/mL ( \pm EP) de B. thuringiensis var. kurstaki após incubação em caldo nutriente $\left(30 \pm 2^{\circ} \mathrm{C}, 150\right.$ $\mathrm{rpm}, 24 \mathrm{~h})$ com fungicidas em diferentes concentrações.

\begin{tabular}{llccc}
\hline Tratamentos & Conc. L/ha ${ }^{1}$ & $\begin{array}{c}\text { Média UFC/mL } \\
\left(\times 10^{5}\right)\end{array}$ & $\begin{array}{c}\text { \% Relação à } \\
\text { Testemunha }{ }^{2}\end{array}$ & $\begin{array}{c}\text { Dif. Inóc. Inic. } \\
\left(\times 10^{5}\right) \text { UFC/ mL }\end{array}$ \\
\hline Epoxiconazole & $0,25(1 / 2 \mathrm{R})$ & $1180 \pm 2,32 \mathrm{a}$ & $+333,8$ & +1178 \\
Azoxystrobin & $0,2(1 / 2 \mathrm{R})$ & $662 \pm 1,39 \mathrm{~b}$ & $+143,4$ & +660 \\
Epoxiconazole & $0,5(\mathrm{R})$ & $564 \pm 2,24 \mathrm{~b}$ & $+107,3$ & +562 \\
Testemunha & - & $272 \pm 1,25 \mathrm{c}$ & - & +270 \\
Carbendazin & $0,25(1 / 2 \mathrm{R})$ & $123 \pm 0,59 \mathrm{~d}$ & $-54,8$ & +121 \\
Carbendazin & $0,5(\mathrm{R})$ & $63 \pm 0,34 \mathrm{e}$ & $-76,9$ & +61 \\
Azoxystrobin & $0,4(\mathrm{R})$ & $34 \pm 0,18 \mathrm{e}$ & $-87,5$ & -32 \\
Tebuconazole & $0,5(\mathrm{R})$ & $0,0 \mathrm{f}$ & - & - \\
Tebuconazole & $0,25(1 / 2 \mathrm{R})$ & $0,0 \mathrm{f}$ & - & - \\
Fentin Hidróxido & $0,5(\mathrm{R})$ & $0,0 \mathrm{f}$ & - & - \\
Fentin Hidróxido & $0,25(1 / 2 \mathrm{R})$ & $0,0 \mathrm{f}$ & & - \\
\hline CV & & 9,49 & & - \\
\hline
\end{tabular}

$\mathrm{CV}(\%)$

9,49

Médias seguidas pela mesma letra minúscula na coluna, não diferem significativamente entre si pelo teste de Tukey $(\alpha=5 \%)$.

${ }^{1}$ Concentração utilizada dos produtos: $\mathrm{R}=$ recomendada, $1 / 2 \mathrm{R}=$ metade da recomendada.

${ }^{2}$ Fórmula: [(Média de UFC/mL do tratamento/ Média de UFC/mL da testemunha $\times 100$ ) - 100], sendo os valores positivos para aumento de UFC e negativos para a redução em relação à testemunha.

${ }^{3}$ Cálculo não realizado por não haver formação de UFC.

${ }^{4}$ Diferença do inóculo inicial = [(Média de UFC $/ \mathrm{mL}$ do patógeno inoculada antes da incubação nos frascos Erlenmeyer $)$ - (Média de UFC/mL do patógeno obtida após 24 h de incubação )], sendo os valores positivos para aumento de UFC e negativos para redução com relação ao inóculo inicial. 


\section{Capacidade de metabolização}

Nenhum dos tratamentos diferiu significativamente da testemunha. Entretanto, epoxiconazole, em ambas as concentrações, e azoxystrobin e carbendazin, na metade da concentração recomendada, apresentaram médias de UFC/mL superiores à testemunha, com crescimento variando de 35 a $100 \%$, quando comparados à testemunha (Tabela 4).

Por outro lado, nos demais tratamentos, com exceção de carbendazin, na concentração recomendada, houve redução na média deUFC/mLquando comparados à testemunha, chegando a $65 \%$ no caso de tebuconazole, na metade da concentração recomendada (Tabela 4).

Em todos os tratamentos houve um aumento do $\mathrm{pH}$ do meio de cultura, porém sem atingir níveis que poderiam danificar a atividade metabólica da célula (Tabela 4).

Houve um aumento da população bacteriana em relação ao inóculo inicial, exceto para tebuconazole, na metade da concentração recomendada. Além disso, para epoxiconazole, em ambas as concentrações, e azoxystrobin e carbendazin, na metade da concentração, houve metabolização com aumento populacional da bactéria. Assim, pode-se inferir que os fungicidas seja o ingrediente ativo ou algum componente da formulação, pode ser utilizado como nutriente por Btk, corroborando SutTER et al. (1971) que observaram resultados semelhantes com os inseticidas diazinona e malationa.

Ocrescimento da testemunha pode ser justificado pela quantidade de energia armazenada na célula, a qual permitiu sua reprodução nesse período, já que o meio de incubação de tais células, para tal, constou somente de água.

\section{Efeito dos fungicidas sobre esporos}

A maioria dos fungicidas foi compatível com os esporos. $\mathrm{O}$ produto tebuconazole, na concentração recomendada, foi o que apresentou as maiores médias, em ambos os tempos avaliados, diferindo significativamente da testemunha no tempo de duas horas, sendo, portanto, um produto que estimula a germinação de esporos de Btk. Por outrolado, fentin hidróxido foi o produto que apresentou a maior redução na germinação de esporos, em ambos os tempos e ambas as concentrações, diferindo estatisticamente de todos os outros tratamentos (Tabela 5). Os demais tratamentos apresentaram médias de UFC/mL significativamente iguais à testemunha no tempo de uma hora (Tabela 5)

Tabela 4 - Média de UFC/mL ( \pm EP) de B. thuringiensis var. kurstaki após incubação $\left(30 \pm 2^{\circ} \mathrm{C}, 150 \mathrm{rpm}, 24 \mathrm{~h}\right)$ com água e fungicidas em diferentes concentrações e $\mathrm{pH}$ inicial e final.

\begin{tabular}{|c|c|c|c|c|c|c|}
\hline \multirow[t]{2}{*}{ Tratamento } & \multirow[t]{2}{*}{ Conc. L/ha ${ }^{1}$} & \multirow{2}{*}{$\begin{array}{l}\text { Média UFC } / \mathrm{mL} \\
\qquad\left(\times 10^{4}\right)\end{array}$} & \multirow{2}{*}{$\begin{array}{l}\% \text { Rel. } \\
\text { Test. }^{2}\end{array}$} & \multirow{2}{*}{$\begin{array}{c}\text { Dif. Inóc. Inic. }{ }^{3} \\
\left(\times 10^{4}\right) \text { UFC/ mL }\end{array}$} & \multicolumn{2}{|c|}{$\mathrm{pH}$} \\
\hline & & & & & $0 \mathrm{~h}$ & $24 \mathrm{~h}$ \\
\hline Testemunha & - & $34 \pm 0,56 a b c$ & - & +20 & 6,65 & 7,50 \\
\hline Epoxiconazole & $0,5(\mathrm{R})$ & $68 \pm 0,37 a$ & +100 & +54 & 6,80 & 7,65 \\
\hline Azoxystrobin & $0,2(1 / 2 R)$ & $52 \pm 0,52 \mathrm{ab}$ & +53 & +38 & 6,67 & 7,63 \\
\hline Carbendazin & $0,25(1 / 2 R)$ & $50 \pm 0,75 a b c$ & +47 & +36 & 6,75 & 7,66 \\
\hline Epoxiconazole & $0,25(1 / 2 R)$ & $46 \pm 0,58 \mathrm{abc}$ & +35 & +32 & 6,70 & 7,68 \\
\hline Carbendazin & $0,5(\mathrm{R})$ & $34 \pm 0,30 \mathrm{abc}$ & 0 & +20 & 6,85 & 7,70 \\
\hline Azoxystrobin & $0,4(\mathrm{R})$ & $32 \pm 0,30 \mathrm{abc}$ & -6 & +18 & 6,85 & 7,68 \\
\hline Fentin Hidróxido & $0,5(\mathrm{R})$ & $22 \pm 0,23 \mathrm{bc}$ & -35 & +8 & 7,36 & 7,75 \\
\hline Fentin Hidróxido & $0,25(1 / 2 R)$ & $18 \pm 0,38 b c$ & -47 & +4 & 7,03 & 7,75 \\
\hline Tebuconazole & $0,5(\mathrm{R})$ & $16 \pm 0,25 b c$ & -53 & +2 & 6,15 & 7,28 \\
\hline Tebuconazole & $0,25(1 / 2 \mathrm{R})$ & $12 \pm 0,22 c$ & -65 & -2 & 6,40 & 7,28 \\
\hline $\mathrm{CV}(\%)$ & & 49,32 & & & & \\
\hline
\end{tabular}

Médias seguidas pela mesma letra minúscula na coluna, não diferem significativamente entre si pelo teste de Tukey $(\alpha=.5 \%)$.

${ }^{1}$ Concentração dos produtos: $\mathrm{R}=$ recomendada, $1 / 2 \mathrm{R}=$ metade da recomendada.

${ }^{2}$ Relação a testemunha, fórmula: [(Média de UFC/mL do tratamento/ Média de UFC/mL da testemunha × 100 ) - 100], sendo os valores positivos para aumento de UFC e negativos para a redução em relação à testemunha.

${ }^{3}$ Diferença do inóculo inicial = [(Média de UFC $/ \mathrm{mL}$ do patógeno inoculada antes da incubação nos frascos Erlenmeyer $)$ - (Média de UFC/mL do patógeno obtida após $24 \mathrm{~h}$ de incubação )], sendo os valores positivos para aumento de UFC e negativos para redução com relação ao inóculo inicial. 
A maioria dos tratamentos apresentou tendência deredução da germinação dos esporos com oaumento dotempodecontato destes com os fungicidas, corroborando com CHeNetal.(1974) para inseticidase Bt. Houve diferença significativa apenas para carbendazin, na metade da concentração recomendada, e fentin hidróxido, na concentração recomendada (Tabela 5).

Por outro lado, os tratamentos azoxystrobin, em ambas as concentrações, tebuconazole, na concentração recomendada, e a testemunha apresentaram um aumento na germinação ao longo do tempo, com diferença significativa apenas para azoxystrobin, na metade da concentração recomendada, e tebuconazole, na concentração recomendada (Tabela5). Tal variação nasconcentrações dos produtos também foiobservada por MoRRIS (1975) em testes com inseticidas.

\section{Comparação entre as técnicas de avaliação}

Grande parte dos trabalhos de compatibilidade entre produtos fitossanitários e entomopatógenos é desenvolvida in vitro, cuja vantagem é a exposição máxima dos entomopatógenos aos produtos. Assim, detectada a inocuidade em condições de laboratório a aplicação em campo é praticamente garantida com relação ao efeito testado. Contudo, a toxicidade in vitro não significa que o mesmo se refletirá em campo (Alves et al., 1998).

A técnica de avaliação por meio de discos de papel foi desenvolvida na década de 1940, visando maior praticidade para os estudos dos efeitos de antibióti- cos sobre os microrganismos. De acordo comKONEMAN et al. (2001), quando o disco impregnado entra em contato com a superfície úmida do meio de cultura, a água é absorvida para o papel numa velocidade maior do que a difusão da substância no meio circundante. Assim, a velocidade deextração da substância para fora do papel é maior do que a difusão desta para o meio de cultura, de forma que a concentração do produto adjacente ao disco pode exceder a do próprio disco. Ainda, segundo os autores, à medida que aumenta a distância em relação ao disco, há uma redução logarítmica da concentração da substância, de forma que quando é alcançada uma massa celular bacteriana crítica, a atividade inibitória é ultrapassada e aparece o crescimento bacteriano.

Embora a maioria dos fungicidas tenha sido considerada compatível, exceto fentin hidróxido, ressalta-se que a avaliação com discos é apenas visual, sem a quantificação do inóculo, sendo justificada a necessidade de se complementar com outras técnicas de avaliação, que levem em consideração a padronização do inóculo e quantificação da bactéria/mL.

Além disso, não há necessariamente uma relação entre a velocidade de difusão in vitro com a atividade antimicrobiana in vivo, ou seja, o tamanho do halo não está relacionado com a sua atividade antimicrobiana. Assim, se o produto for tóxico ao microrganismo haverá a formação de um halo de inibição ao redor do disco de papel, cujo tamanho variará conforme a capacidade de difusão do produto no meio de cultura (Konemam et al., 2001).

Tabela 5 - Média de UFC/mL ( \pm EP) de B. thuringiensis var. kurstaki com 1 e $2 \mathrm{~h}$ de incubação $\left(30 \pm 2^{\circ} \mathrm{C}\right.$ e $\left.150 \mathrm{rpm}\right) \mathrm{com}$ água e fungicidas em diferentes concentrações.

\begin{tabular}{|c|c|c|c|c|c|}
\hline \multirow[t]{2}{*}{ Tratamento } & \multirow[t]{2}{*}{ Conc. L/ha ${ }^{1}$} & \multicolumn{2}{|c|}{ Germinação (1h) } & \multicolumn{2}{|c|}{ Germinação (2h) } \\
\hline & & $\mathrm{UFC} / \mathrm{mL}\left(\times 10^{5}\right)$ & $\%$ Rel. Test. $^{2}$ & $\mathrm{UFC} / \mathrm{mL}\left(\mathrm{x} 10^{5}\right)$ & $\%$ Rel. Test. $^{2}$ \\
\hline Testemunha & & $618 \pm 0,51 \mathrm{Aab}$ & - & $676 \pm 1,06 \mathrm{Ab}$ & - \\
\hline Tebuconazole & $0,5(\mathrm{R})$ & $738 \pm 1,08 \mathrm{Ba}$ & $+19,40$ & $792 \pm 1,95 \mathrm{Aa}$ & $+17,16$ \\
\hline Epoxiconazole & $0,25(1 / 2 R)$ & $664 \pm 0,68 \mathrm{Aab}$ & $+7,44$ & $662 \pm 1,67 \mathrm{Ab}$ & $-2,07$ \\
\hline Carbendazin & $0,5(\mathrm{R})$ & $650 \pm 1,39 \mathrm{Aab}$ & $+5,18$ & $646 \pm 0,42 \mathrm{Ab}$ & $-4,44$ \\
\hline Tebuconazole & $0,25(1 / 2 \mathrm{R})$ & $650 \pm 1,39 \mathrm{Aab}$ & $+5,18$ & $622 \pm 1,14 \mathrm{Ab}$ & $-7,99$ \\
\hline Carbendazin & $0,25(1 / 2 \mathrm{R})$ & $646 \pm 0,80 \mathrm{Aab}$ & $+4,53$ & $526 \pm 0,86 \mathrm{Bb}$ & $-22,19$ \\
\hline Azoxystrobin & $0,4(\mathrm{R})$ & $638 \pm 0,71 \mathrm{Aab}$ & $+3,24$ & $642 \pm 1,98 \mathrm{Ab}$ & $-5,03$ \\
\hline Epoxiconazole & $0,5(\mathrm{R})$ & $636 \pm 0,79 \mathrm{Aab}$ & $+2,91$ & $632 \pm 0,48 \mathrm{Ab}$ & $-6,51$ \\
\hline Azoxystrobin & $0,2(1 / 2 R)$ & $608 \pm 0,78 \mathrm{Bb}$ & $-1,62$ & $646 \pm 1,39 \mathrm{Ab}$ & $-4,44$ \\
\hline Fentin Hidróxido & $0,25(1 / 2 \mathrm{R})$ & $20 \pm 0,42 \mathrm{Ac}$ & $-96,80$ & $14 \pm 0,28 \mathrm{Ac}$ & $-97,93$ \\
\hline Fentin Hidróxido & $0,5(\mathrm{R})$ & $18 \pm 0,20 \mathrm{Ac}$ & - 97,10 & $6 \pm 0,18 \mathrm{Bc}$ & $-99,11$ \\
\hline
\end{tabular}

Médias seguidas pela mesma letra maiúscula na linha e minúscula na coluna, não diferem significativamente entre si pelo teste de Tukey (á $=5 \%$ ).

${ }^{1}$ Concentração utilizada dos produtos: $\mathrm{R}=$ recomendada, $1 / 2 \mathrm{R}=$ metade da recomendada.

${ }^{2}$ Relação a testemunha, fórmula $=$ [(Média de UFC $/ \mathrm{mL}$ do tratamento/ Média de UFC $/ \mathrm{mL}$ da testemunha × 100 $\left.)-100\right]$, sendo os valores positivos para aumento de UFC e negativos para a redução em relação a testemunha. 
A maioria dos tratamentos apresentou halo de inibição com algumas UFC. Segundo KonEmAn et al. (2001), podem ser colônias mutantes oriundas de células mais resistentes ou o cultivo não é puro, o que não é o caso. Assim, tal fato associado à difusão irregular do produto no meio de cultura, justifica a formação de halos com UFC, em maior ou menor quantidade.

Com relação à técnica na qual se mistura os fungicidas ao meio de cultura antes da solidificação, epoxiconazole e azoxystrobin, em ambas as concentrações, foram incompatíveis com a célula, diferindo do resultado obtido na avaliação com discos de papel. Por outro lado, carbendazin, independente da concentração, foi compatível na técnica dos discos de papel, sendo que na técnica de mistura dos produtos ao meio de cultura apresentou média de UFC/mL significativamente igual à testemunha somente na metade da concentração recomendada. Tais resultados diferem dos obtidos por SALERno et al. (1999), que em trabalho semelhante, verificaram que carbendazin, na concentração recomendada, foi compatível com 16 cepas de Bt, inclusive Btk. A diferença nos trabalhos se refere à formulação, sendo queSALERNO et al. (1999) utilizaram pó molhável e no seguinte trabalho foi utilizado suspensão concentrada.

Também, por meio da técnica de mistura dos produtos ao meio de cultura BATISTA FILHO et al. (2001) avaliaram o efeito de inseticidas em Bt. Verificaram que o efeito variou de acordo com o produto e concentração utilizada, sendo que diafentiuron na concentração mínima estimulou significativamente a germinação. Por outro lado, com o produto imidacloprida a média de UFC/mL foi maior no tratamento com a maior concentração do produto. Além disso, monocrotofós e deltrametrina, na concentração máxima recomendada, promoveram inibição total da germinação.

Embora com resultados diferentes, ambas as técnicas mencionadas anteriormente são semelhantes quanto à condição de oxigenação. Porém, além de não estar relacionada com a capacidade de difusão dos produtos no meio de cultura, a técnica de mistura permite a quantificação do patógeno, sendo, portanto a mais confiável. Além disso, a distribuição mais uniforme dos produtosé garantida na técnica de mistura ao meio de cultura, em relação a dos discos impregnados. Há que se considerar ainda a quantidade de inóculo empregada, quefoi maior na técnica dos discosimpregnados. Assim, além de uma menor quantidade de inóculo empregada, evidenciou-se que a mistura dos produtos fitossanitários ao meio de cultura causou um efeito inibitório no crescimento bacteriano.

Ao comparar a técnica dos produtos misturados ao meiodeculturaea técnica deincubaçãoemmeiolíquido, o fator oxigenação pode ser relacionado aos resultados, como também observado nos trabalhos de IGNATENKOet al. (1983) para células e AvignONE-RossA et al. (1992) para esporos e cristais. Embora Btk seja uma bactéria anaerobicamente facultativa, de acordo com MoRAEs et al. (1980), há a necessidade de uma condição ideal de oxigenação, pois tanto a ausência como o excesso de oxigênio inibe o crescimento bacteriano.

De acordo com PINTo (comunicação pessoal), os efeitos negativos obtidos neste trabalho, na técnica de mistura dos produtos fitossanitários ao meio de cultura em relação à incubação em meio líquido, podem ser justificados pela diferença de oxigenação, sendo que a difusão do oxigênio em meio com agitação é maior. Além disso, no caso da técnica com os produtos misturados ao meio de cultura, as células se encontram num estado quorum sensi, ou seja, muito próximas umas às outras. Nessa condição, há uma constante troca de sinais, localmente na colônia, com produção de metabólitos secundários, que podem ter efeito inibitório sobre as células. Por sua vez, essa troca de sinais, no caso da incubação em meio líquido, se dá através do meio de cultura, minimizandooefeito dos metabólitos.

Neste sentido, com referência à compatibilidade entre a célula e os fungicidas, a avaliação em meio líquidoéa mais confiável, pois possibilita a dispersão dos metabólitos secundários, garante constante oxigenação, e total distribuição do produto no meio de cultura. Isto associado ao constante contato do patógeno com o substrato, aumenta a possibilidade de metabolização dos componentes do meio e conseqüente crescimento populacional.

Os testes com células, exceto o teste de metabolização, simulam o que poderia ocorrer na hemolinfa do inseto, com a ingestão simultânea da bactéria e do produto fitossanitário, o que justifica a importância destes.

Entretanto, o teste com esporos e cristais considera a compatibilidade de um ponto de vista aplicado, uma vez que estes são os princípios ativos dos bioinseticidas.

Assim, os resultados obtidos na avaliação da compatibilidade dos esporos com os fungicidas foram muito satisfatórios, pois todos os tratamentos, exceto fentin hidróxido, foram compatíveis. Na maioriados tratamentos houve tendênciade redução da germinação dos esporos com o aumento do tempo de incubação. Além disso, os tratamentos com a metade da concentração recomendada apresentaram as maiores médias de UFC/mL.

Em todas as técnicas utilizadas para testar a compatibilidade com a célula e na técnica utilizada para a avaliação da compatibilidade com o esporo, os resultados foram os mesmos somente para fentin hidróxido. Por outro lado, uma grande variação foi observada para tebuconazole, pois este foi classificado como parcialmente compatível na técnica dos 
discos impregnados e incompatível nas técnicas de mistura dos produtos ao meio de cultura em placas e meio líquido. Porém, apresentou a maior média de germinação de esporos, na concentração recomendada, em ambos os tempos.

SILVA\&Neves (2005) também verificaram variação entre técnicas, concentrações e produtos utilizados, em trabalho com fungos. Assim, os resultados obtidos pelos autores, juntamente com os obtidos neste trabalho, chamam a atenção também para a adequabilidade das técnicas empregadas na avaliação da compatibilidade entre produtos fitossanitários e microrganismos de forma geral, para que se possa atestar com segurança a toxicidade dos produtos.

A avaliação da compatibilidade entre produtos fitossanitários, esporos e cristais de Btkéfundamental para o sucesso da estratégia de manejo, pois o contato entre estes é uma condição real. Assim, os resultados sugerem, exceto para fentin hidróxido, a utilização conjunta de esporos de Btk e os referidos fungicidas para a aplicação conjunta. Porém, estudos em campo e semi-campo, e também com cristais, são necessários para a confirmação da eficiência dessa estratégia.

\section{CONCLUSÕES}

O efeito dos fungicidasvaria conforme a técnica de avaliação empregada, o estágio/fase do ciclo de vida do patógeno (célula e esporo), e as concentrações.

A técnica de avaliação em meio líquido é a mais confiável para testes de compatibilidade entre fungicidas e células de Btk.

A célula de Btk tem capacidade de metabolizar os fungicidas testados.

Fentin hidróxido é incompatível com os esporos de Btk.

\section{REFERÊNCIAS}

Alves, S.B.; Mbino Júnior, A.; Almeida, J.E.M. Produtos fitossanitários e entomopatógenos. In: Alves, S.B. (Ed.). Controle microbiano de insetos. 2.ed. Piracicaba: FEALQ, 1998. cap. 8, p.217-238.

Avignone-Rossa, C.; ArCas, J.; Mgnone, C. Bacillus thuringiensis growth, sporulation and ä-endotoxin production in oxygen limited and non-limeted cultures. World Journal of Microbiology and Biotechnology, v.8, n.3, p.301-304, 1992.

Batista Filho, A.; Almeida, J.E.M.; Lamas, C. Effect of Thiamethoxam on Entomopathogenic Microorganisms. Neotropical Entomology, v.30, n.3, p.437-447, 2001.

Chen, K.; FunKe, B.R.; Schulz, J.T.; CARLson, R.B.; Proshold, F.I. Effects of certain organophosphate and carbamate inseticides on Bacillus thuringiensis. Journal of Economic Entomology, v.67, n.4, p.471-473, 1974.
DOUGHERTY,E.M.;R EICHELDERFER, C.F.;F AUST, R.M.Sensitivity of Bacillus thuringiensis var. thuringiensis to various insecticides and herbicides. Journal of Invertebrate Pathology, v.17, n.2, p.292-293, 1971.

FERREIRA, D.F. Sistema Sisvar para análises estatísticas. Disponível em: <http:/ / www.dex.ufla.br/danielff/ dff02.htm>. Acesso em: 23 dez. 2005.

Ignatenko, Yu.N.; Sakharova, Z.V.; Khovrychev, M.P.; SHevtsov, V.V. Efect of temperature and aeration on growth and spore formation in Bacillus thuringiensis. Microbiology, v.52, n.5, p.553-556, 1983.

Jimenez, J.; Acosta, N.; FernANDEZ, R. Efecto de insecticidas y fungicidas sobre la actividade biologica de preparaciones de Bacillus thuringiensis. Protección de Plantas, v.12, n.1, p.45-59, 1989.

Koneman, E.W.; Allen, S.D.; Jande, W.M.; Shereckenbuger, P.C.; J Rwinn, W.C. Provas de Sensibilidade a Agentes Antimicrobianos. In:_. Diagnóstico Microbilógico. Rio de Janeiro: Medici, 2001. Cap. 15, 1465p.

Moraes, I.O.; Santana, M.H.A.; HoKKa, C.O. The influence of oxygen concentration on microbial insecticide production. London: Bergman Press, 1980. p.75-79.

Moraes, I.O.; CaPalbo, D.M.F.; Arruda, R.O.M Produção de bactérias entomopatogênicas In: ALVES, S.B. (Ed.). Controle microbiano de insetos, Piracicaba: FEALQ, 1998. Cap. 26, p.815-843.

Morris, O.N. Effect of Some Chemical Insecticides on the Germination and Repelication of CommercialBacillus thuringiensis. Journal of Invertebrate Pathology, v.26,n.2. p.199-204, 1975.

PolAnCZYK, R.A. Estudos de Bacillus thuringiensis Berliner visando ao controle de Spodoptera frugiperda (J.E. Smith). 2004. 144f. Tese (Doutorado Entomologia) - Escola Superior de Agricultura "Luiz de Queiroz" - Universidade deSão Paulo, Piracicaba, 2004. Disponível em: <http:// teses.usp.br>. Acesso em: 18 nov. 2005.

SALERNo, C.; Dias, S.; SAgardoy, M. Efecto de pesticidas sobre cepas de Bacillus thuringiensis bajocondiciones controladas. Revista Argentina de Microbiologia, v.31, p.58-64, 1999.

Silva, R.Z. DA; Neves, P.M.O.J. Techniques and parameters used in compatibility tests between Beauveriabassiana (Bals) Vuill and in vitro phytosanitary products. Pest Management Science, v.61, p.667-674, 2005.

Sosa-Gomes, D.R.; MoscardI, F. Importância das interações entreagroquímicoseentomopatógenos em programas de MIP. In:SIMPÓSIO DE CONTROLE BIOLÓGICO, 8., 2003, São Pedro, SP. Resumos . São Pedro: 2003. p.59.

Sutter, G.R.; Abrahanson, M.D.; Hamilton, E.W.; Vick, I.D. Compatibility of Bacillus thuringiensis var. Kurstaki and Chemical inseticides. 1. Effect of Insecticide Doses on Bacterial Replication Rate. Journal of Economic Entomology, v.64, n.6, p.1348-1350, 1971.

VAladares-Inglis, M.C.C.; Shiler, W.; Souza, M.T. de Engenharia genética de microrganismos agentes de controle biológico. In: Melo, I.S.; Azevedo, J.L. (Eds.). Controle biológico, Jaguariúna: Embrapa Meio Ambiente, 1998. cap 7, p.201-230.

Recebido em 31/5/06

Aceito em 18/9/06 